\title{
INFLUENCE OF SELENIUM ON MONO SODIUM GLUTAMATE AS FOOD ADDITIVE INDUCED HEPATOTOXICITY AND TESTICULAR TOXICITY IN ADULT ALBINO RATS
}

\author{
Eman El-Sayed H. Khayal, ${ }^{1}$ Zeinab A. M. Mohammed ${ }^{1}$ and Mona Mostafa Ahmed ${ }^{2}$ \\ ${ }^{1}$ Forensic Medicine and Clinical Toxicology Department, Faculty of Medicine, Zagazig \\ University, Egypt. \\ ${ }^{2}$ Pathology Department, Faculty of Medicine, Zagazig University, Egypt.
}

\begin{abstract}
Background: Mono sodium glutamate (MSG) is commonly used as a flavor enhancer. Many studies showed toxic effects of MSG on different organs. Selenium (Se) is reported to possess a strong antioxidant property. The aim of this work was to evaluate the role of selenium on hepatotoxicity, testicular toxicity induced by MSG in adult albino rats. Material and Methods: study included 55 male albino rats for 8 weeks. Rats were divided into four groups, group I(control group) consisted of 22 rats equally and randomly subdivided into 2 subgroups: Ia (-ve control group), Ib (+ve control group) received distilled water. Group II (Se group) consisted of 11 rats received sodium biselenite at a dose of $(0.5 \mathrm{ml} / \mathrm{kg} /$ day/orally $)$ dissolved in distilled water. Group III (MSG treated group) consisted of 11 rats received MSG at a dose of $(830 \mathrm{mg} / \mathrm{kg} /$ day/ orally) dissolved in distilled water. Group IV (MSG and Se treated group) consisted of 11 rats treated in the previous doses. After 8 weeks, the rats were submitted to estimate the serum levels of alanine transaminase (ALT) \& gamma glutamyle transferase (GGT) levels and testosterone hormone level. Then the anesthetized rats were sacrificed \& specimens from the liver and testes were taken for determination of histopathological study, immunohistochemical staining for caspase 3, oxidative stress markers [malondialdehyde (MDA) \& glutathione peroxidase (GPx)] and sperm count. Results showed in MSG group significantly increased serum ALT, GGT \& significantly decreased in serum testosterone, sperm count with marked histopathological changes in the liver and testis and caspase 3 activities was significantly increased in testicular and liver tissue. Also, it significantly increased MDA level and decreased GPx activity in (liver and testicular tissues). Administration of Se along with MSG produced partial improvement of hepatic and testicular morphological changes, reduction in caspase 3 expression with beneficial effect on liver and testicular parameters, In addition, it decreased MDA level and increased GPX activity in (liver and testicular tissues). In conclusion, the results confirmed the hepatic and testicular toxicity of MSG through oxidative stress. Selenium has partial protective effects against MSG induced hepatic, testicular toxicity through its anti oxidant and its anti apoptotic effects.
\end{abstract} testis.

Keywords: mono sodium glutamate, selenium, oxidative stress, caspase 3, liver, 


\section{INTRODUCTION}

Food additives are substances added to food to preserve flavor and enhance its taste and appearance (Kunkel et al., 2004).

One of the famous and widely used food additives in the developed and developing world is mono sodium glutamate (MSG). It can be found in different amounts in many food products such as meat, fish, milk, emulsified fat and oil, pasta, cocoa, chocolate products and fruit juice (Walke and Lupien, 2000; Eweka et al., 2011). So, millions of people are used and consumed it all over the world (John, 2006 and Gheller, 2017).

Food processors and manufacturers usually do not list the amount of MSG on their packaging, so, there is no way to know the mount of MSG consumed daily by the normal person (Erb, 2006).

Mono sodium glutamate is not a natural material. It's manufactured from glutamic acid (Raben et al., 2003). After oral intake, it is rapidly absorbed from gastrointestinal tract by active transport causing an elevation in the blood plasma level of glutamate (Schwartz, 2004). This glutamate will go to any glutamate receptors, which are present in many organs as brain, liver, lung, kidney, testis and spleen inducing adverse effects on these organs (Erb, 2006; Soliman, 2011).

Many studies showed the toxic effects of MSG on different organs including neuroexcitotoxiciy, retinal degeneration (Swelim, 2004), atrial fibrillation, ventricular tachycardia and arrhythmias (Raiten et al., 1995), renal toxicity (Marwa and Manal, 2011), obesity (Thomas et al., 2009), genotoxicity to a variety of organs and tissues (Farombi and Onyema, 2006) and female infertility (Eweka and Om lniabohs, 2010).

Oxidation-reduction (redox) homeostasis, like $\mathrm{pH}$ control, is necessary for life (Jones and Sies, 2015). Oxidative stress occurred when excessive production of reactive oxygen species cannot be counteracted by the action of antioxidants, also, as a result of disturbance cell redox balance. This will result in function modulation in cellular lipids, proteins, or DNA leading to various diseases (Pisoschi and Pop, 2015).

Selenium (Se) is an essential dietary trace element, which plays a significant role in a number of biological processes in humans and other species (Saito et al., 2003).

Selenium can protect the organs against oxidative damage by enhancing activities of antioxidant enzymes, increasing contents of antioxidants and inhibiting lipid peroxidation, so it has a strong antioxidant property (Su et al., 2008).

Caspases are a family of endoproteases, which have critical links in cell regulatory cascades controlling inflammation and cell death. They are produced as inert zymogens then activated when the cell receives apoptotic stimuli. So that, they are used as a marker for cellular damage in many diseases (McIlwain et al., 2013).

The aim of the present study was to evaluate the ameliorative role of selenium on changes induced by repeated oral administrations of $\mathrm{MSG}$ on the liver and testis in adult male albino rats through detection of the changes in serum blood levels of alanine transaminase (ALT) \& Gamma glutamyle transferase (GGT) levels, and serum testosterone hormone level. Oxidative stress markers 
[malondialdehyde (MDA) \& glutathione peroxidase $(\mathrm{GPx})]$ in liver and testicular tissues were evaluated. Histopathological examination and

\section{MATERIAL AND METHODS}

(I) Material:

a) Chemical:

Mono sodium glutamate $(\mathrm{C} 5 \mathrm{H} 9 \mathrm{NO} 4 \cdot \mathrm{Na})$ with purity $99 \%$ was obtained from Alam market, Egypt under the license of Ajinomoto Co. Inc., Tokyo, Japan. It was provided in a white crystal form. Selenium was obtained from El- Nasr Co., Egypt as sodium biselenite in powder form. Distilled water was obtained from ElSaad Pharmacy, Egypt and used as a solvent for MSG and sodium biselenite. Sodium citrate solution (2.9\%) and physiological saline solution $(0.9 \%)$ were obtained from El- Nasr Co. Egypt and used for epididymal spermatozoal examination.

b) Animals:

Adult male albino rats, each weighed about 180-200 gm were obtained from animal house of the Faculty of Veterinary Medicine, Zagazig University.

\section{(II)Methods:}

\section{1- Experimental Design:}

This study was carried on 55 adult male albino rats. The rats were divided into four group as follows: Group I: consist of 22 rats equally and randomly subdivided into: Group Ia (Negative control group): received only regular diet and tap water. Group Ib (Positive control group): received distilled water daily orally. Group II (Se treated group): 11 rats received sodium biselenite $(0.5 \mathrm{mg} / \mathrm{kg}$ ) (Gropper et al., 2009) dissolved in distilled water daily orally by gavage. Group III (MSG treated group): 11 rats received immunohistochemical staining for caspase 3 in hepatic and testicular tissues. Sperm cell count were also evaluated.

MSG (830 mg/kg) (1/20 of LD50) dissolved in distilled water daily orally by gavage. Oral LD50 of MSG in rats $=16600 \mathrm{mg} / \mathrm{kg}$ body weight (Richard and Lewis, 1990). Group IV (MSG \& Se treated group): 11 rats received MSG $(830 \mathrm{mg} / \mathrm{kg}$ ) dissolved in distilled water daily orally by gavage and sodium biselenite $(0.5 \mathrm{mg} / \mathrm{kg})$ dissolved in distilled water daily orally by gavage.

The study extended for 8 weeks. Twenty four hours after the last dose of treatments, blood samples were obtained from the retro-orbital plexus as described by Joslin (2009) from all rats of all groups to estimate the serum levels of ALT according to colorimetric method proposed by Reitman and Frankel (1957), GGT according to colorimetric method proposed by Szewczuk (1988) and serum testosterone hormone by ELISA according to Zirkin and Chen (2000).

Then the anaesthetized rats were sacrificed, the liver and testicular tissue samples were dissected and used for:

a) Estimation of GPX and MDA according to methods proposed by of Paglia and Valentine (1967) and Ohkawa et al. (1979) respectively.

b) Histopathological examination: All tissue samples were fixed with $10 \%$ formalin. Consecutive $5-\mu \mathrm{m}$ thick sections from formalin-fixed, paraffinembedded tissue blocks were prepared and stained with hematoxylin and eosin (H\&E) for light microscope examination according to the method described by (Horobin and Bancroft, 1998). 
c) Immunohistochemistry for Caspase-3: Immunohistochemical staining of anti-caspase-3 antibody was performed by streptoavidin-biotin. Sections were cut with thickness of 4 $\mu \mathrm{m}$ and deparaffinized then incubated with fresh $0.3 \%$ hydrogen peroxide in methanol for $30 \mathrm{~min}$ at room temperature. The specimens were then incubated with polyclonal anti-caspase3 (RB-1197-P0, Thermo-Fisher Fermont USA) as the primary antibody at a 1:100 dilution. The specimens were counterstained with hematoxylin. Negative controls were prepared by substituting normal mouse serum for each primary antibody. For evaluation of caspase 3 the stain intensity was divided into 3 grades defined as: $1+$ weak or negative, $2+$ moderate, $3+$ strong.

d) Seminal samples obtained from the rat epididymis were done as described by Kuriyama et al. (2005) for counting sperms according to the method reported by Assayed et al. (2008).

\section{2- Methods of Statistical} Analysis:

SPSS Software program was used. Mean values \pm standard deviations (SD) were calculated, $t$ test, ANOVA (F) test followed by least significant difference test (LSD test) were performed. Descriptive data were compared by chi-square test. $\mathrm{P}$ value of less than 0.05 was considered significant.

\section{RESULTS}

No statistically significant differences were observed in the studied parameters between negative, positive control groups and selenium group (Tables 1, 2).

After 8 weeks of administration of MSG, there was highly significant elevation in the mean values of serum ALT, GGT and in the mean values of hepatic MDA with highly significant reduction in the mean values of hepatic GPx $(\mathrm{P}<0.001)$ as compared to control group ( Tables 3,4).

These biochemical changes were associated with histopathological changes in the hepatic tissues in the form of marked vacuolation with some pyknotic nuclei. The sinusoidal spaces showed congestion with extravasation of red blood cells. Central vein dilatation with congestion and homogenous infiltration with numerous kupffer cells were detected. Proliferation of bile ducts with cellular infiltration were detected (Plate I, figs C1, C2, C3).

Administration of selenium with MSG produced partial improvement in the mean values of serum ALT, serum GGT, hepatic MDA and hepatic GPx (Tables 3, 4). In addition, the histopathological examination of hepatic tissues showed regression of the above changes that occurred after MSG administration in different degrees. There were almost normal lobular architecture and normal hepatocytes with some pyknotic nuclei. Dilated central vein is still present (Plate I, fig D).

According to caspase 3 expression in hepatic tissues, there was a highly significant difference between different groups where MSG group showed increased caspase 3 activity, $54.5 \%$ of them had scored (3) or strong expressions $\mathrm{P}<0.001$ (Plate II, fig C) and (Table 7 ), with administration of selenium with MSG, there was lowering of caspase 3 expression in line with the reduction of necroinflammatory reaction and $54.5 \%$ of them had scored (2) or moderate 
expressions $\mathrm{P}<0.001$ when compared to control sections (Plate II, fig D) and (Table 7).

After 8 weeks of MSG administration, there were highly significant reduction in the mean values of serum testosterone, sperm count and in the mean values of testicular GPX with highly significant elevations in the mean values testicular MDA when compared with other groups of the study $(\mathrm{P}<0.001)$ (Tables 5, 6).

These biochemical changes were associated with histopathological changes in the testicular tissues in the form of disorganization of seminiferous tubules, some tubules showed decreased numbers of spermatogonia, spermatogenic cells and sperms, dark pyknotic nuclei was detected, separation of basement membranes which is most probably rich in fluids, homogenous infiltration in interstitial tissue were detected (Plate III, fig C1, C2).

Administration of selenium with MSG produced partial improvement in the mean values of serum testosterone, sperm count and in the mean values testicular GPx and MDA (Tables 5, 6).

In addition, the histopathological examination of testicular tissues showed improvement of seminiferous tubules cells and showing the near normal structure of seminiferous cells, basement membrane and germinal layers are well developed. Whereas some seminiferous tubules kept normal appearance and lined by multiple layers of spermatogenic cells with appearance of sperms, some were affected with discontinuation of basement membranes and some pyknotic nuclei (Plate III, fig D.

According to caspase 3 expression in testicular tissues, there was a highly significant difference between different groups where MSG group showed increased caspase 3 activity, $72.7 \%$ of them had scored (3) or strong expressions $\mathrm{P}<0.001$ (Plate IV, fig C) and (Table 8), with administration of selenium with MSG, there was lowering of caspase 3 expression and 45.4 of them had scored (2) or moderate expressions $\mathrm{P}<0.001$ when compared to control sections (Plate IV, fig D) and (Table 8). 
Table (1): Statistical comparison between the mean values of liver function tests [serum ALT (IU/L) \& GGT (IU/L)] and the mean values of hepatic MDA (nmol/g) and hepatic GPx (ng/g) of adult albino rats among negative, positive control groups and selenium group by the end of $8^{\text {th }}$ week of administration using ANOVA test.

\begin{tabular}{|c|c|c|c|c|c|}
\hline $\begin{array}{l}\text { Group } \\
\text { Variable } \\
\end{array}$ & $\begin{array}{c}\text { Group Ia } \\
\text { (-ve) } \text { control }(\mathrm{N}=11)\end{array}$ & $\begin{array}{c}\text { Group Ib } \\
(+\mathrm{ve}) \text { control }(\mathrm{N}=11)\end{array}$ & $\begin{array}{c}\text { Group II } \\
(\mathrm{Se})(\mathbf{N}=\mathbf{1 1})\end{array}$ & $\mathbf{F}$ & $\mathbf{P}$ \\
\hline $\begin{array}{c}\text { ALT (IU/L): } \\
\text { Mean } \pm S D \\
\text { Range }\end{array}$ & $\begin{array}{c}49.87 \pm 0.31 \\
49.4-50.3 \\
\end{array}$ & $\begin{array}{c}49.75 \pm 0.21 \\
48.1-50.1 \\
\end{array}$ & $\begin{array}{c}49.58 \pm 0.29 \\
48.5-51 \\
\end{array}$ & 3.12 & $\begin{array}{l}0.06 \\
\text { NS }\end{array}$ \\
\hline $\begin{array}{c}\text { GGT }(\mathbf{I U} / \mathbf{L}): \\
\text { Mean } \pm S D \\
\text { Range }\end{array}$ & $\begin{array}{c}48.08 \pm 0.37 \\
47.4-48.6 \\
\end{array}$ & $\begin{array}{c}48.26 \pm 0.31 \\
48.5-49.2 \\
\end{array}$ & $\begin{array}{c}47.93 \pm 0.35 \\
47.1-48 \\
\end{array}$ & 2.53 & $\begin{array}{c}0.09 \\
\text { NS }\end{array}$ \\
\hline $\begin{array}{c}\text { MDA liver }(\mathbf{n m o l} / \mathbf{g}) \\
\text { Mean } \pm S D \\
\text { Range } \\
\end{array}$ & $\begin{array}{c}19.65 \pm 0.23 \\
19.3-20 \\
\end{array}$ & $\begin{array}{c}19.66 \pm 0.20 \\
19.4-20 \\
\end{array}$ & $\begin{array}{c}19.70 \pm 0.18 \\
18.6-19.2 \\
\end{array}$ & 0.18 & $\begin{array}{c}0.83 \\
\text { NS } \\
\end{array}$ \\
\hline $\begin{array}{c}\text { GPx liver }(\mathbf{n g} / \mathbf{g}): \\
\text { Mean } \pm S D \\
\text { Range }\end{array}$ & $\begin{array}{c}21.02 \pm 0.18 \\
20.7-21.3\end{array}$ & $\begin{array}{c}20.95 \pm 0.16 \\
20.7-21.2\end{array}$ & $\begin{array}{c}21.09 \pm 0.18 \\
20.1-21\end{array}$ & 1.79 & $\begin{array}{l}0.19 \\
\text { NS }\end{array}$ \\
\hline
\end{tabular}

ALT: Alanine transaminase GGT: Gamma glutamyl transferase GPx: Glutathione peroxidase ANOVA: Analysis of variance $\quad \mathrm{N}$ : Number of rats in each group.

NS: Non significant as $\mathrm{P}$ value $>0.05$.

Table (2): Statistical comparison between the mean values of serum testosterone level $(\mathrm{ng} / \mathrm{ml})$, the mean values of sperm cell count $\left.\left(\mathrm{x} 10^{6} / \mathrm{mm}^{3}\right)\right]$ and mean values of MDA (nmol/g) and GPx (ng/g) in testicular tissues of adult albino rats among negative, positive control groups and selenium group by the end of $8^{\text {th }}$ week of administration using ANOVA test.

\begin{tabular}{|c|c|c|c|c|c|}
\hline $\begin{array}{c}\text { Group } \\
\text { Variable }\end{array}$ & $\begin{array}{c}\text { Group Ia } \\
\text { (-ve) control } \\
(\mathbf{N}=11) \\
\end{array}$ & $\begin{array}{c}\text { Group Ib } \\
\text { (+ve) control } \\
(\mathrm{N}=11) \\
\end{array}$ & $\begin{array}{c}\text { Group II } \\
(\mathrm{Se}) \\
(\mathbf{N}=\mathbf{1 1}) \\
\end{array}$ & $\mathbf{F}$ & $\mathbf{P}$ \\
\hline $\begin{array}{c}\text { Testosterone: }(\mathbf{n g} / \mathbf{m l}) \\
\text { Mean } \pm S D \\
\text { Range } \\
\end{array}$ & $\begin{array}{c}6.33 \pm 0.31 \\
5.9-6.9 \\
\end{array}$ & $\begin{array}{c}6.42 \pm 0.36 \\
5.9-6.9 \\
\end{array}$ & $\begin{array}{c}6.50 \pm 0.27 \\
6.1-7.0 \\
\end{array}$ & 0.80 & $\begin{array}{c}0.46 \\
\text { NS } \\
\end{array}$ \\
\hline $\begin{array}{c}\text { Sperm count: } \\
\left(\mathbf{x 1 0}^{6} / \mathbf{m m}^{\mathbf{3}}\right) \\
\text { Mean } \pm S D \\
\text { Range } \\
\end{array}$ & $\begin{array}{l}141.16 \pm 0.21 \\
140.8-141.5\end{array}$ & $\begin{array}{l}140.95 \pm 0.34 \\
140.2-141.3\end{array}$ & $\begin{array}{l}140.85 \pm 0.35 \\
140.1-141.2\end{array}$ & 2.93 & $\begin{array}{l}0.07 \\
\text { NS }\end{array}$ \\
\hline $\begin{array}{c}\text { MDA testis }(\mathbf{n m o l} / \mathrm{g}) \\
\text { Mean } \pm \mathrm{SD} \\
\text { Range }\end{array}$ & $\begin{array}{c}19.65 \pm 0.23 \\
19.3-20 \\
\end{array}$ & $\begin{array}{c}19.66 \pm 0.20 \\
19.4-20 \\
\end{array}$ & $\begin{array}{c}19.70 \pm 0.18 \\
18.6-19.2 \\
\end{array}$ & 0.18 & $\begin{array}{c}0.83 \\
\mathrm{NS} \\
\end{array}$ \\
\hline $\begin{array}{c}\text { GPx testis }(\mathbf{n g} / \mathbf{g}): \\
\text { Mean } \pm S D \\
\text { Range }\end{array}$ & $\begin{array}{c}21.02 \pm 0.18 \\
20.7-21.3\end{array}$ & $\begin{array}{c}20.95 \pm 0.16 \\
20.7-21.2\end{array}$ & $\begin{array}{c}21.09 \pm 0.18 \\
20.1-21\end{array}$ & 1.79 & $\begin{array}{c}0.19 \\
\mathrm{NS}\end{array}$ \\
\hline
\end{tabular}

MDA: Malondialdehyde glutamate Se: Selenium
GPx: Glutathione peroxidase MSG: Mono sodium ANOVA: Analysis of variance $\mathrm{N}$ : Number of rats in each group. NS: Non significant as $\mathrm{P}$ value $>0.05$. 
Table (3): Statistical comparison between the mean values of liver function tests [serum ALT (IU/L) \& GGT (IU/L)] and the mean values of hepatic MDA (nmol/g) and hepatic GPx (ng/g) of adult albino rats among (-ve) control (group Ia), MSG (group III) and MSG+Se (group IV) after 8 weeks of administration using ANOVA test.

\begin{tabular}{|c|c|c|c|c|c|}
\hline $\begin{array}{c}\text { Group } \\
\text { Variable }\end{array}$ & $\begin{array}{c}\text { Group Ia } \\
\text { (-ve) control } \\
(\mathbf{N}=11)\end{array}$ & $\begin{array}{c}\text { Group III } \\
\text { (MSG) } \\
\text { (N=11) }\end{array}$ & $\begin{array}{c}\text { Group IV } \\
(\text { MSG+ Se }) \\
(\mathbf{N}=11)\end{array}$ & $\mathbf{F}$ & $\mathbf{P}$ \\
\hline $\begin{array}{l}\text { ALT (IU/L): } \\
\text { Mean } \pm S D \\
\text { Range }\end{array}$ & $\begin{array}{c}49.87 \pm 0.31 \\
49.4-50.3\end{array}$ & $\begin{array}{c}145.24 \pm 0.45 \\
144.5-146\end{array}$ & $\begin{array}{c}93.91 \pm 0.39 \\
93.1-94.5\end{array}$ & 167.1 & $<0.001 * *$ \\
\hline $\begin{array}{c}\text { GGT (IU/L): } \\
\text { Mean } \pm S D \\
\text { Range }\end{array}$ & $\begin{array}{c}48.08 \pm 0.37 \\
47.4-48.6\end{array}$ & $\begin{array}{c}80.28 \pm 0.37 \\
79.8-80.9\end{array}$ & $\begin{array}{c}60.08 \pm 0.25 \\
59.7-60.5\end{array}$ & 259.8 & $<0.001 * *$ \\
\hline $\begin{array}{c}\text { MDA liver(nmol/g) } \\
\text { Mean } \pm S D \\
\text { Range } \\
\end{array}$ & $\begin{array}{c}90.39 \pm 0.32 \\
89.9-90.8\end{array}$ & $\begin{array}{l}148.67 \pm 0.37 \\
148.1-149.2\end{array}$ & $\begin{array}{l}110.11 \pm 0.20 \\
109.6-110.9\end{array}$ & 103.82 & $<0.001 * *$ \\
\hline $\begin{array}{c}\text { GPx liver }(\mathbf{n g} / \mathbf{m l}): \\
\text { Mean } \pm S D \\
\text { Range }\end{array}$ & $\begin{array}{c}19.65 \pm 0.23 \\
19.3-20\end{array}$ & $\begin{array}{c}9.81 \pm 0.18 \\
9.2-10.1\end{array}$ & $\begin{array}{c}16.17 \pm 0.23 \\
15.8-16.5\end{array}$ & 594.5 & $<0.001 * *$ \\
\hline
\end{tabular}

ALT: Alanine transaminase $\quad$ GGT: Gamma Glutamyl transferase GPx:

Glutathione peroxidase

MSG: Mono sodium glutamate Se: Selenium ANOVA: Analysis of variance

$\mathrm{N}$ : Number of rats in each group. **: highly significant $(\mathrm{P}:<0.001)$ 
Table (4): Least significant difference test (LSD) for comparison of changes of the mean values of ALT, GGT and the mean values of hepatic MDA and hepatic GPx in-between groups after 8 weeks.

\begin{tabular}{|c|c|c|c|}
\hline parameter & Group & $\begin{array}{c}\text { Group III (MSG) } \\
\qquad(\mathrm{N}=11)\end{array}$ & $\begin{array}{c}\text { Group IV (MSG+ Se) } \\
(\mathrm{N}=11)\end{array}$ \\
\hline \multirow[t]{3}{*}{ ALT (IU/L) } & $\begin{array}{c}\text { Group Ia (-ve Control) } \\
\text { (N=11) } \\
\text { Mean } \pm \text { SD }(49.87 \pm 0.31)\end{array}$ & $<0.001 * *$ & $<0.05 * *$ \\
\hline & $\begin{array}{c}\text { Group III (MSG) } \\
\text { (N=11) } \\
\text { Mean } \pm \text { SD }(145.24 \pm 0.45)\end{array}$ & & $<0.001 * *$ \\
\hline & $\begin{array}{c}\text { Group IV (MSG+ Se }) \\
(\mathbf{N = 1 1 )} \\
\text { Mean } \pm \text { SD }(93.91 \pm 0.39)\end{array}$ & $<0.001 * *$ & \\
\hline \multirow[t]{3}{*}{ GGT (IU/L) } & $\begin{array}{c}\text { Group Ia (-ve Control) } \\
\text { (N=11) } \\
\text { Mean } \pm \text { SD }(48.08 \pm 0.37)\end{array}$ & $<0.001 * *$ & $<0.05 * *$ \\
\hline & $\begin{array}{c}\text { Group III (MSG) } \\
(\mathbf{N}=\mathbf{1 1}) \\
\text { Mean } \pm \mathbf{S D}(80.28 \pm 0.37)\end{array}$ & & $<0.001 * *$ \\
\hline & $\begin{array}{c}\text { Group IV (MSG+ Se) } \\
(\mathbf{N}=\mathbf{1 1}) \\
\text { Mean } \pm \text { SD }(60.08 \pm 0.25) \\
\end{array}$ & $<0.001 * *$ & \\
\hline \multirow{3}{*}{$\begin{array}{l}\text { MDA liver } \\
(\mathbf{n m o l} / \mathbf{g})\end{array}$} & $\begin{array}{c}\text { Group Ia (-ve Control) } \\
(\mathbf{N}=\mathbf{1 1}) \\
\text { Mean } \pm \text { SD }(90.39 \pm 0.32)\end{array}$ & $<0.001 * *$ & $<0.05^{*}$ \\
\hline & $\begin{array}{c}\text { Group III (MSG) } \\
\text { (N=11) } \\
\text { Mean } \pm \text { SD }(148.67 \pm 0.37)\end{array}$ & & $<0.001 * *$ \\
\hline & $\begin{array}{c}\text { Group IV (MSG+ Se) } \\
(\mathbf{N}=\mathbf{1 1}) \\
\text { Mean } \pm \text { SD }(110.11 \pm 0.20) \\
\end{array}$ & $<0.001 * *$ & \\
\hline \multirow{3}{*}{$\begin{array}{l}\text { GPx liver } \\
\text { (ng/g) }\end{array}$} & $\begin{array}{c}\text { Group Ia (-ve Control) } \\
\text { (N=11) } \\
\text { Mean } \pm \text { SD }(19.65 \pm 0.23)\end{array}$ & $<0.001 * *$ & $<0.05^{*}$ \\
\hline & $\begin{array}{c}\text { Group III (MSG) } \\
\text { (N=11) } \\
\text { Mean } \pm \text { SD }(9.81 \pm 0.18)\end{array}$ & & $<0.001 * *$ \\
\hline & $\begin{array}{c}\text { Group IV (MSG+ Se) } \\
(\mathbf{N}=\mathbf{1 1}) \\
\text { Mean } \pm \text { SD }(16.17 \pm 0.23)\end{array}$ & $<0.001 * *$ & \\
\hline
\end{tabular}
ALT: Alanine transaminase
GGT: Gamma Glutamyl transferase
MDA:

Malondialdehyde

GPx: Glutathione peroxidase

MSG: Mono sodium

glutamate Se: Selenium

$\mathrm{N}$ : Number of rats in each group $\quad *$ : $\mathrm{P}<0.05$ significant $\quad * *$ : $\mathrm{P}<0.001$ highly significant 
Table (5): Statistical comparison between the mean values of serum testosterone level $(\mathrm{ng} / \mathrm{ml})$, the mean values of sperm cell count $\left.\left(\times 10^{6} / \mathrm{mm}^{3}\right)\right]$ and mean values of MDA (nmol/g) and GPx (ng/g) in testicular tissues of adult albino rats among (ve) control (group Ia), MSG (group III) and MSG+Se (group IV)after 8 weeks of administration using ANOVA test.

\begin{tabular}{|c|c|c|c|c|c|}
\hline $\begin{array}{l}\text { Group } \\
\text { Variable }\end{array}$ & $\begin{array}{c}\text { Group Ia } \\
\text { (-ve) control } \\
(\mathbf{N}=11) \\
\end{array}$ & $\begin{array}{c}\text { Group III } \\
\text { (MSG) } \\
(\mathrm{N}=11) \\
\end{array}$ & $\begin{array}{c}\text { Group IV } \\
(\mathrm{MSG}+\mathrm{Se}) \\
(\mathrm{N}=11) \\
\end{array}$ & $\mathbf{F}$ & $\mathbf{P}$ \\
\hline $\begin{array}{l}\text { Testosterone: } \\
\text { (ng/ml) } \\
\text { Mean } \pm S D \\
\text { Range }\end{array}$ & $\begin{array}{c}6.33 \pm 0.31 \\
5.9-6.9\end{array}$ & $\begin{array}{c}1.97 \pm 0.17 \\
1.7-2.2\end{array}$ & $\begin{array}{c}3.98 \pm 0.32 \\
3.5-4.0\end{array}$ & 691.1 & $<0.001 * *$ \\
\hline $\begin{array}{l}\text { Sperm count: } \\
\left(\mathbf{x 1 0} \% \mathbf{m m}^{\mathbf{3}}\right) \\
\text { Mean } \pm S D \\
\text { Range } \\
\end{array}$ & $\begin{array}{l}141.16 \pm 0.21 \\
140.8-141.5\end{array}$ & $\begin{array}{c}74.53 \pm 0.33 \\
74.1-75.1\end{array}$ & $\begin{array}{c}120.07 \pm 0.32 \\
119.1-120 \\
\end{array}$ & 149.8 & $<0.001 * *$ \\
\hline $\begin{array}{c}\text { MDA testis } \\
(\mathrm{nmol} / \mathrm{g}) \\
\text { Mean } \pm \text { SD } \\
\text { Range } \\
\end{array}$ & $\begin{array}{c}89.45 \pm 0.21 \\
89.1-89.8 \\
\end{array}$ & $\begin{array}{c}136.45 \pm 0.28 \\
136-136.9 \\
\end{array}$ & $\begin{array}{l}109.55 \pm 0.27 \\
109.1-109.9 \\
\end{array}$ & 93.92 & $<0.001 * *$ \\
\hline $\begin{array}{c}\text { GPx testis }(\mathbf{n g} / \mathbf{g}): \\
\text { Mean } \pm S D \\
\text { Range }\end{array}$ & $\begin{array}{c}21.02 \pm 0.18 \\
20.7-21.3\end{array}$ & $\begin{array}{c}10.62 \pm 0.28 \\
10.1-10.9\end{array}$ & $\begin{array}{c}17.07 \pm 0.33 \\
16.5-17.2\end{array}$ & 413.9 & $<0.001 * *$ \\
\hline
\end{tabular}

MDA: Malondialdehyde GPx: Glutathione peroxidase $\quad$ MSG: Mono sodium glutamate

Se: Selenium ANOVA: Analysis of variance $\quad$ N: Number of rats in each group

**: highly significant $(\mathrm{P}:<0.001)$ 
Table (6): Least significance difference (LSD) for comparison of the changes of the mean values of testosterone, sperm count, testicular MDA and GPx in-between groups after 8 weeks of administration.

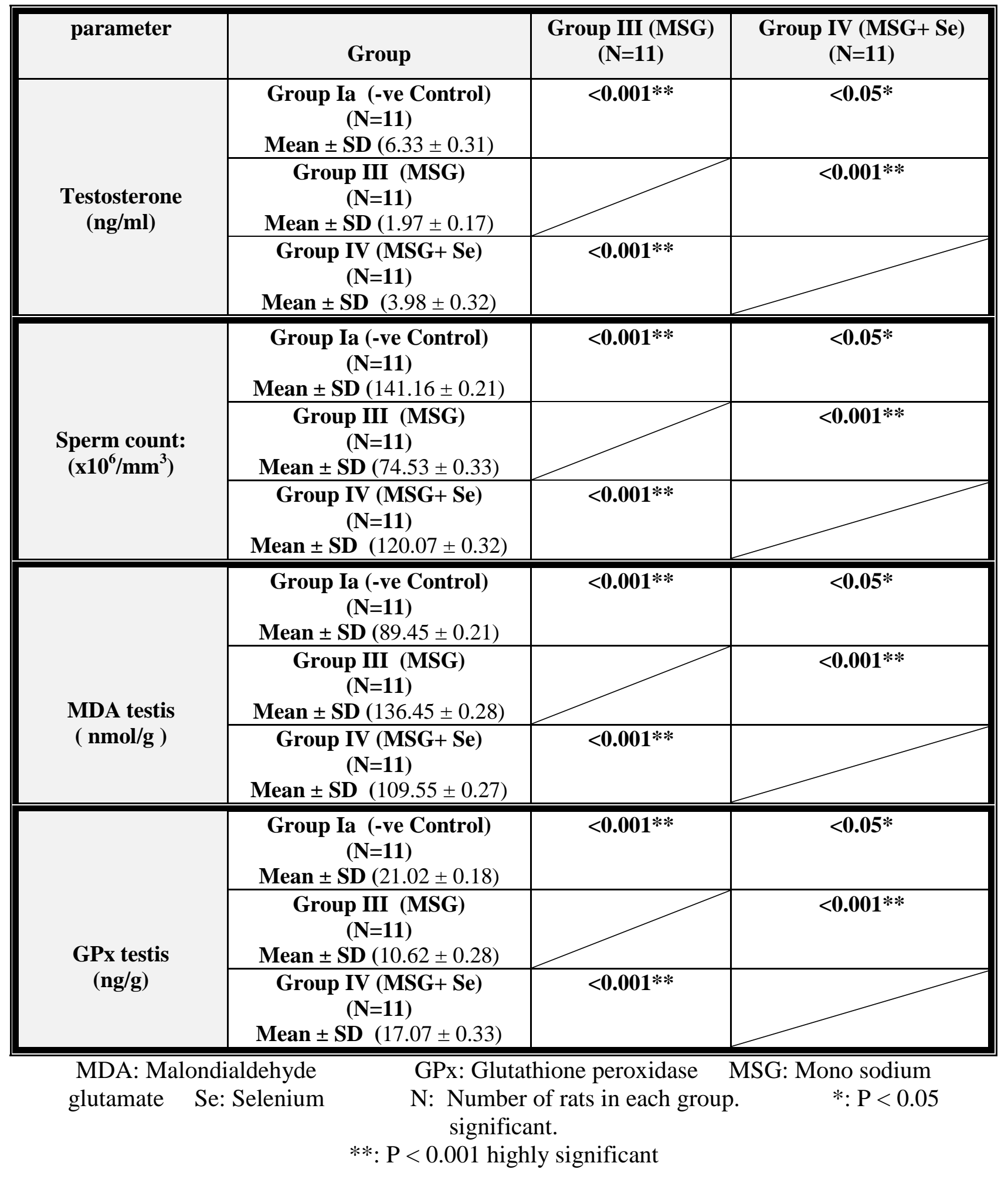


Table (7): Chi-square test statistical analysis of caspase 3 expressions in hepatic tissues of different studied groups.

\begin{tabular}{|c|c|c|c|c|c|c|c|c|c|c|c|}
\hline \multirow{2}{*}{$\begin{array}{l}\text { Group } \\
\text { Caspase } 3 \\
\text { expression } \\
\text { s }\end{array}$} & \multicolumn{2}{|c|}{$\begin{array}{l}\text { Group Ia } \\
\text { (-ve) control } \\
(\mathbf{N}=11)\end{array}$} & \multicolumn{2}{|c|}{$\begin{array}{c}\text { Group Ib } \\
(+ \text { ve) control } \\
(\mathbf{N}=11)\end{array}$} & \multicolumn{2}{|c|}{$\begin{array}{c}\text { Group II } \\
(\mathrm{Se}) \\
(\mathrm{N}=11) \\
\end{array}$} & \multicolumn{2}{|c|}{$\begin{array}{c}\text { Group III } \\
\text { (MSG) } \\
(\mathbf{N}=\mathbf{1 1})\end{array}$} & \multicolumn{2}{|c|}{$\begin{array}{c}\text { Group IV } \\
(\mathrm{MSG}+\mathrm{Se}) \\
(\mathrm{N}=11)\end{array}$} & \multirow[t]{2}{*}{$\mathbf{P}$} \\
\hline & No & $\%$ & No & $\%$ & No & $\%$ & No & $\%$ & No & $\%$ & \\
\hline Grade 1 & 11 & 100 & 10 & 90.9 & 11 & 100 & 2 & 18.2 & 3 & 27.3 & $<0.001 * *$ \\
\hline Grade 2 & 0 & 0 & 1 & 9.1 & 0 & 0 & 3 & 27.3 & 6 & 54.5 & $<0.001 * *$ \\
\hline Grade 3 & 0 & 0 & 0 & 0 & 0 & 0 & 6 & 54.5 & 2 & 18.2 & $<0.001 * *$ \\
\hline
\end{tabular}

MSG: Mono sodium glutamate **: highly significant $(\mathrm{P}:<0.001)$

Se: Selenium $\mathbf{N}$ : Number of rats in each group. $\mathrm{X}^{2}=\mathbf{4 0 . 9 7 3}$

Table (8): Chi-square test statistical analysis of caspase 3 expressions in testicular tissues of different studied groups.

\begin{tabular}{|c|c|c|c|c|c|c|c|c|c|c|c|}
\hline Group & \multicolumn{2}{|c|}{$\begin{array}{c}\text { Group Ia } \\
\text { (-ve) control } \\
\text { (N=11) }\end{array}$} & $\begin{array}{c}\text { Group Ib } \\
\text { (+ve) } \\
\text { control } \\
\text { Caspase 3 } \\
\text { expressions }\end{array}$ & No & $\%$ & \multicolumn{2}{c|}{$\begin{array}{c}\text { Group II } \\
\text { (Se) } \\
\text { (N=11) }\end{array}$} & $\begin{array}{c}\text { Group III } \\
\text { (MSG) } \\
(\mathbf{N = 1 1 )}\end{array}$ & $\begin{array}{c}\text { Group IV } \\
\text { (MSG+ Se) } \\
\text { (N=11) }\end{array}$ & P \\
\hline Grade 1 & 10 & 90.9 & 11 & 100 & 10 & 90.9 & 1 & 9.1 & 4 & 36.4 & $<\mathbf{0 . 0 0 1} * *$ \\
\hline Grade 2 & 1 & 9.1 & 0 & 0 & 1 & 9.1 & 2 & 18.2 & 5 & 45.4 & $<\mathbf{0 . 0 0 1} * *$ \\
\hline Grade 3 & 0 & 0 & 0 & 0 & 0 & 0 & 8 & 72.7 & 2 & 18.2 & $<\mathbf{0 . 0 0 1} * *$ \\
\hline
\end{tabular}

MSG: Mono sodium glutamate

Se: Selenium **: highly significant $(\mathrm{P}:<0.001)$

$\mathrm{N}$ : Number of rats in each group. $X^{2}=43.167$ 


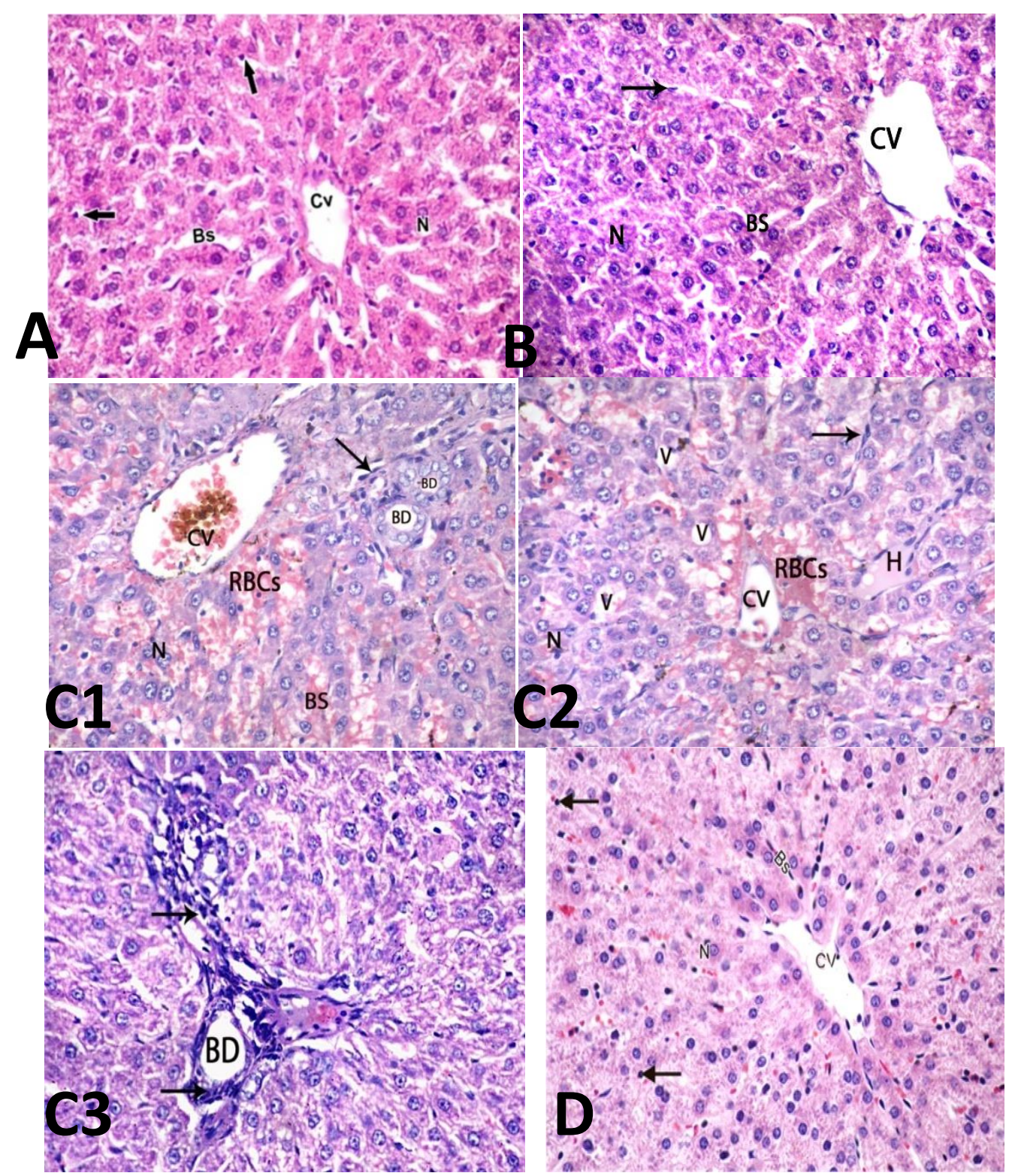

Plate (I): Sections of hepatic lobules obtained from an adult male albino rat showing:

Figure (A): normal hepatic lobule (control group) (H\&E x400).

Figure (B): hepatocytes separated by blood sinusoids (Bs) lined by kuppfer cells (arrow) and radiating from the central vein (CV) (selenium group) (H\&E x400).

Figure (C1, C2): disorganization of hepatic lobules with loss of normal hepatic architecture, central vein congestion and dilatation (CV), blood sinusoidal congestion (BS) with extra-vasation of red blood cells (RBCs), some pyknotic nuclei $(\mathrm{N})$ and numerous kupffer cells (arrow) were detected. Bile duct proliferation (BD) was detected (Mono sodium glutamate group (III))(H\&E $\mathrm{x} 400)$.

Figure (C3): dilatation of bile duct (BD) with cellular infiltration (arrow) around it Mono sodium glutamate group (III))( (H\&E x1000).

Figure (D) : minimal disorganization of hepatocytes with some pyknotic nuclei $(\mathrm{N})$, minimal blood sinusoidal congestion (BS) with some Kupffer cells (arrow), dilated central vein $(\mathrm{CV})$ is still present (Mono sodium glutamate + Selenium (IV) ) (H\&E x400). 


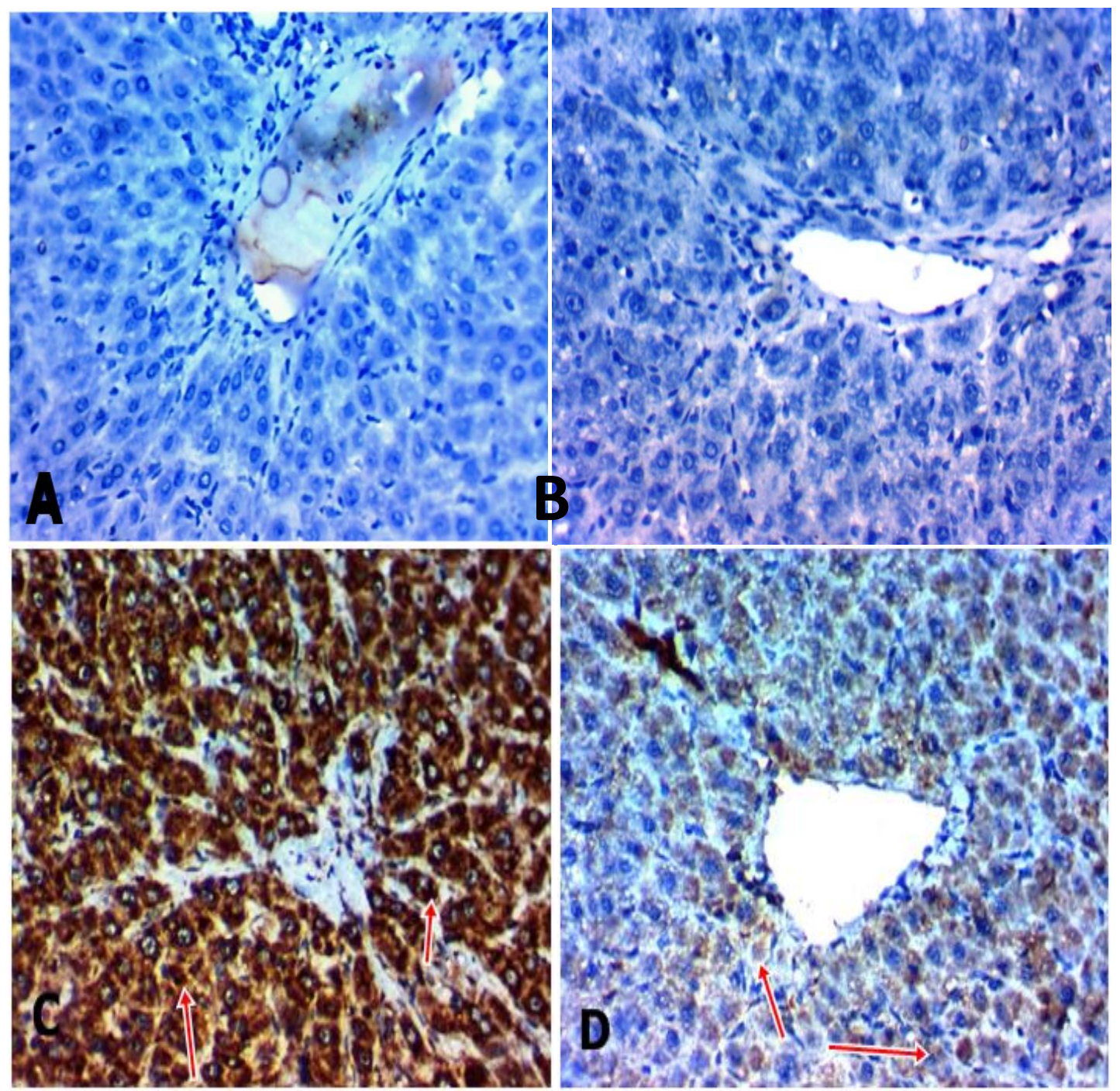

Plate (II) : Immunohistochemical expression of caspase-3 in hepatic tissues obtained from an adult male albino rat (X 400) showed :

Figure (A): hepatocytes negative for Caspase-3 (control group).

Figure (B): hepatocytes negative for Caspase-3 [selenium group(II)].

Figure (B): marked caspase-3 staining, identified by brown staining [mono sodium glutamate group (III)] $(\rightarrow)$.

Figure $(\mathbf{C})$ : decrease in the caspase 3 expression [mono sodium glutamate + selenium $\operatorname{group}(\mathrm{IV})](\rightarrow)$. 


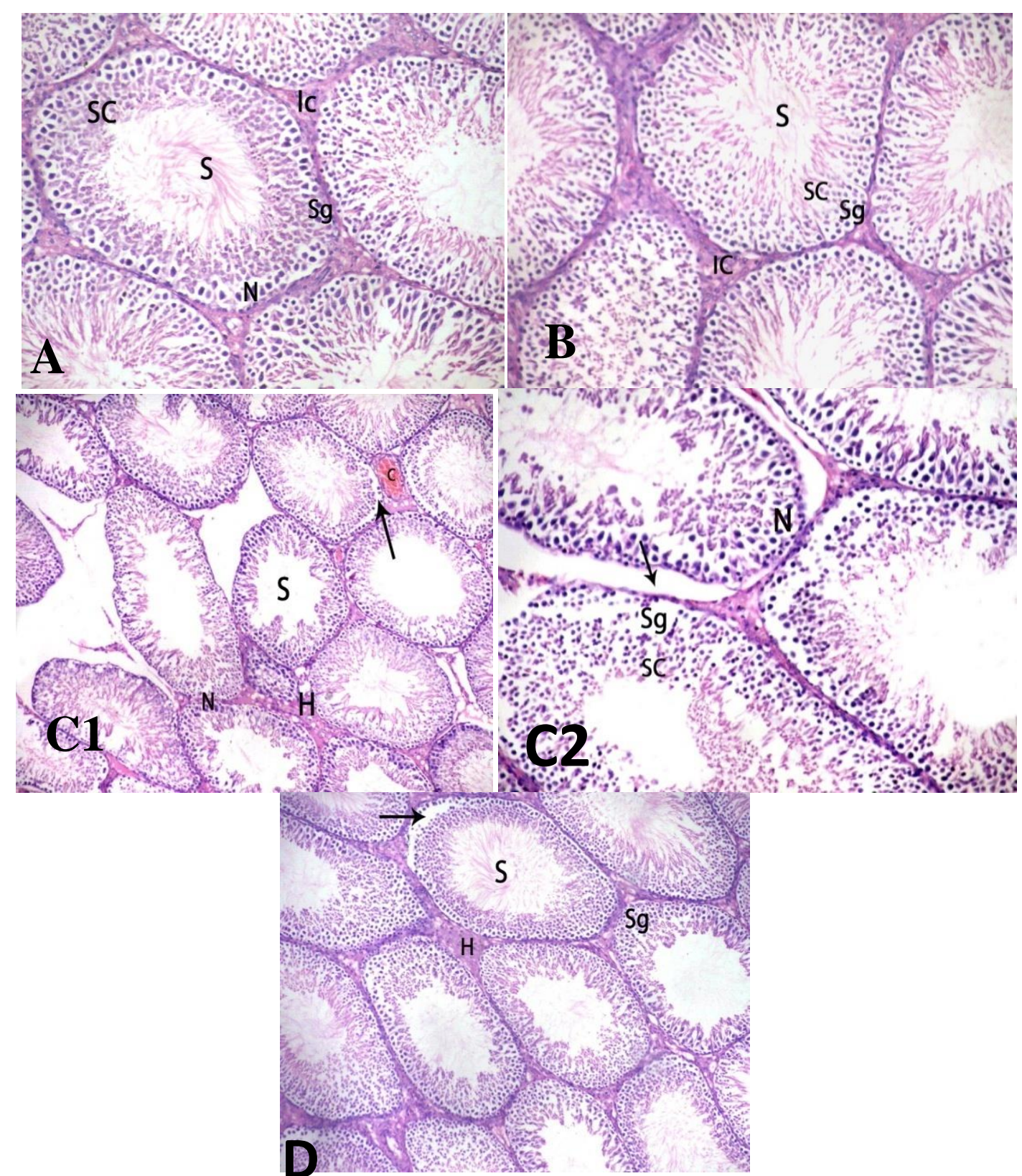

Plate (III) :Sections of testes obtained from an adult male albino rat showing:

Figure (A) : normal testicular tissues (control group) (H\&E x400).

Figure (B) : normal seminiferous tubules lined by spermatogonia $(\mathrm{Sg}$ ) adjacent to the basement membrane and spermatogenic cells (SC). Seminiferous tubules lumen containing sperms (S) with normal interstitial tissue cells (IC) in between [selenium group (II)] (H\&E x400).

Figure (C1) : disorganization of seminiferous tubules with congestion in between (c), separation of basement membrane (arrow), some pyknotic nuclei $(\mathrm{N})$ with few sperms $(\mathrm{S})$, homogenous infiltration was detected $(\mathrm{H})$ [mono sodium glutamate group (III)] (H\&E x200).

Figure (C2) : separation of basement membrane (arrow), some pyknotic nuclei (N) with few spermatogonia (Sg) [mono sodium glutamate group (III)] (H\&E x400).

Figure (D) : minimal disorganization of seminiferous tubules, discontinuation of basement membranes in some areas (arrow), numerous spermatogonia ( $\mathrm{Sg}$ ) and sperms (S), slightly homogenous infiltration in interstitial tissue $(\mathrm{H})$ [mono sodium glutamate + selenium treated group (IV)] (H\&E $\mathbf{x 2 0 0})$. 


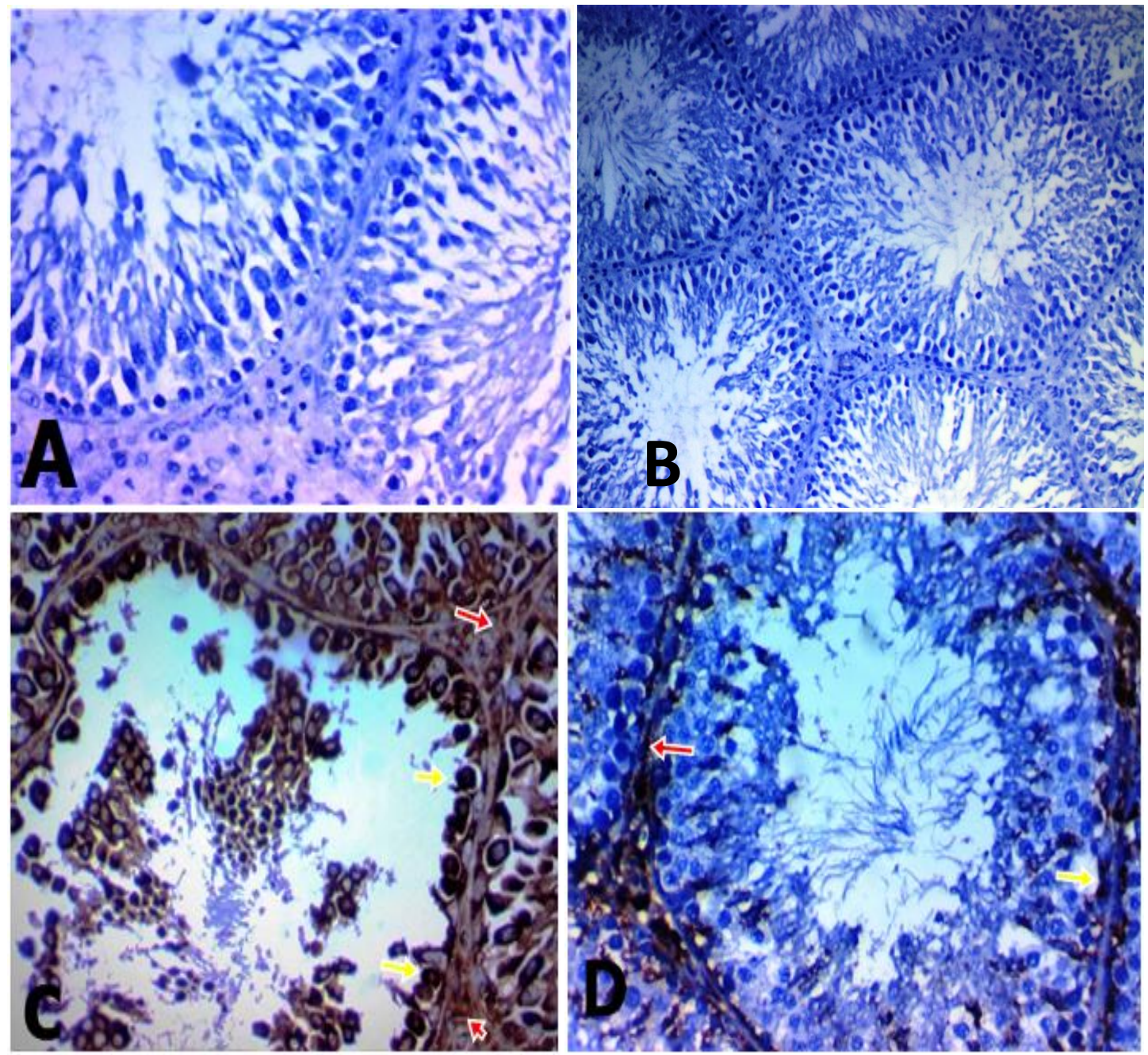

Plate (IV): Immunohistochemical expression of caspase-3 in testicular tissues obtained from an adult male albino rat showed :

Figure (A): negative for caspase 3(control group) (X 400).

Figure (B): negative for caspase 3 [selenium group(II)] (X 200).

Figure (C): The intensity of activated caspase-3 immunostaining (deep brown) is detected in spermatogonia $(\rightarrow)$ and interstitial cells $(\rightarrow)$ [mono sodium glutamate group (III)] (X 400) .

Figure (D): caspase 3 in interstitial cells $(\rightarrow)$ with mild staining in spermatogonia $(\rightarrow)$ [mono sodium glutamate + selenium group (IV)] (X 400).

\section{DISCUSSION}

Mono sodium glutamate is the sodium salt of glutamic acid. Nowadays, it is considered as a silent killer. It is a common flavor enhancer in nutritional industries. It does not catabolize like other amino acids (Shredah, 2017). It has enormous harmful effects on many organs such as, the liver, kidney, immune system, central nervous system and reproductive organs. It can trigger cognitive functions, inducing cytotoxic and genotoxic effects (Husarova and Ostatnikova, 2013).

Liver is the essential organ responsible for the detoxification of 
chemicals and toxins entered in the body (Noeman et al., 2011).

The results of the present study revealed that administration of MSG for 8 weeks induced highly significant elevation in the mean values of serum ALT, GGT, and hepatic MDA with highly significant reduction in the mean values of hepatic GPx.

These results coincided with those of Onyema et al. (2006); Rana et al. (2016); Thomas et al. (2009); Tawfik and Al-Badr (2012); Hamdy et al. ( 2018 ) who found that serum ALT and GGT levels were significantly higher after administration of MSG.

Also, the results of the present study were in a harmony with the studies performed by Foyer et al. (2008); Egbuonu et al. (2009); Contini et al. (2012); Diab and Hamza (2016) who reported that MSG caused increasing in the level of MDA parallel with significant decline in GPx level in hepatic tissues resulted in development of oxidative stress in liver tissues which play an important role in the development of liver damage.

In line with Farombi and Onyema (2006); Eweka et al. (2011); Tawfik and Al-Badr (2012); AbdElla and Mohammed (2016), we found that MSG exposed rat liver exhibit marked vacuolation of hepatocytes with pyknotic nuclei and proliferation of bile ducts with lymphocytic infiltration. The sinusoidal spaces showed congestion with numerous Kupffer cells. Central vein dilatation and congestion were detected.

The results of the present study showed that administration of MSG for 8 weeks induced highly significant strong expression of caspase 3 in hepatic tissues. This result was in a harmony with the results found by (Abd-Ella and Mohammed, 2016).

Many experimental and clinical studies showed that there might be a link between oxidative stress and liver injuries (Berner and Stern, 2004). Farombi and Onyema (2006) Diniz et al. (2005); Thomas et al. (2009) reported that the hepatotoxic effects of MSG were mainly caused by production of reactive oxygen species induced oxidative stress. This oxidative stress leads to changes in membrane properties leading to leakage of the enzymes from the liver cells.

In this study, administration of selenium with MSG produced partial and incomplete improvement of serum GGT, ALT and hepatic MDA, GPX. These biochemical changes are associated also with improvement in the histopathological changes in hepatic tissues with lowering of caspase 3 expression.

In our bodies, there are antioxidant defense mechanisms to deal with oxidative molecules and keep them in balance (Anane and Creppy, 2001).

Selenium is known to enhance antioxidant system by increasing activities of antioxidant enzymes, contents of antioxidants and inhibiting lipid peroxidation. So, it has an important role in the protection against hepatotoxicity induced by many oxidants (Su et al., 2008).

Su et al. (2008); Soudani et al. (2010) ; Saied and Hamza (2014) observed that ALT and GGT levels decreased significantly with improvement in pathological changes in the liver in rats treated daily with sodium biselenite after mercury, 
chromium, isotretinoin administration respectively.

Thapaliya et al. (2014) reported that suppression of caspase 3 resulted in protection of hepatocytes from proinflammatory signals and marked reduction in collagen deposition that is responsible for development of liver fibrosis. Reduction in caspase 3 expression in selenium treated rat suggests its anti-inflammatory role in these cases.

There is a great attention about environmental hazards that can affect reproductive health (Chen et al., 2007).

The testis is an important organ responsible for the production of sperms and testosterone hormone, which is necessary for maintenance of secondary sexual characters and spermatogenesis (Yan et al., 1998).

The results of the present study revealed that administration of $\mathrm{MSG}$ for 8 weeks induced highly significant decrease in the mean values of serum testosterone level, sperm cell count and testicular GPx with highly significant increase in the mean values of hepatic MDA. These biochemical changes are associated with histopathological changes in the testes.

The findings of the current investigation were in agreement with the findings of Franca et al. (2006); Igwebuike et al. (2011); Izuchukwu et al. (2015) who reported that the level of serum testosterone was significantly lower in MSG treated group when compared with control group.

Our obtained data were confirmed by the results obtained by Sener et al. (2003); Tezcan et al. (2003); Seiva et al. (2012); Ni et al. (2016) who reported that MSG caused increasing in the level of MDA parallel with significant decline in GPx level in testicular tissues.

Also, these findings of the current investigation were in agreement with the findings of Nayanatara et al. (2008); Igwebuike et al. (2011); Ekaluo et al. (2013) who found significant reduction in sperm cell count in rats treated with MSG when compared with the control group.

The previous findings are supported by microscopic examination of the testicular tissues, which showed disorganization of seminiferous tubules, decrease number of spermatogonia, spermatogenic cells and sperms, darkly stained pyknotic nuclei, separation of basement membrane, congestion and hyalinization of interstitial tissue after MSG administration. In addition, MSG group showed increased caspase 3 activity.

These histopathological lesions were described by Das and Ghosh (2010); Alalwani (2013); Abd-Ella and Mohammed (2016) who support our findings.

Increased caspase 3 activity in this study is in a harmony with findings described by (Abd-Ella

and

Mohammed, 2016).

Boodnard et al. (2001) explained low serum testosterone level associated with MSG due to destruction of neurons in the hypothalamus. This destruction can result in disturbance of the hypothalamic-pituitary-testis axis that regulate the steroidogenesis of testicular Leydig cells leading to decrease in serum testosterone level.

Moreover, MSG may lower serum cholesterol level, which is a precursor of steroid hormones including testosterone hormone leading to lowering its level (Hu et al., 2010). 
In line with Özyurt et al. (2004); Tremellen (2008); Hamza and AL-Harbi (2014) we found that the biochemical and histopathological changes in testicular tissues occurred after MSG administration are due to disturbance in oxidative defense systems with increase the level of oxidants in the testicular tissues.

In the present study, administration of selenium with MSG produced partial and incomplete improvement of serum testosterone, sperm count and testicular MDA, GPX. These biochemical changes are associated also with improvement in the histopathological changes in testes with lowering of caspase 3 expression.

The findings of the current investigation were in agreement with Gupta et al. (2005); Hamza and ALHarbi (2014) who reported protective effect of selenium against MSG induced testicular toxicity in rats, as selenium improves histopathological changes in testicular tissues induced by MSG with significant reduction in testicular MDA level and marked recovery of testicular GPx level compared to the control group.

Green (2000) mentioned that MSG decrease the activities of antioxidant enzymes with accumulation of free radicals in the organs inducing the lipid peroxidation of the membrane with releasing pro apoptotic proteins into the cytosol, leading to cellular apoptosis. Therefore, the useful strategy to prevent the toxic effects of MSG is the use of antioxidant.

Messaoudi et al. (2010) reported that selenium is an important antioxidant nutrient. It can protect the organs against oxidative damage. This protective effect could be due to its ability to counteract the enhanced lipid peroxidation by trapping, scavenging and changing oxygen free radicals into stable compounds (Marin-Guzman et al., 2000; Salem et al., 2012).

\section{CONCLUSION}

From the above-mentioned results, it can be concluded that monosodium glutamate administration induced toxic effects on liver and testis and the use of selenium had a protective effect against these toxic effects.

It is recommended to increase health education programs about the health impact of food additives especially monosodium glutamate and trial to substitute it by other safer food additives. Also, it is recommended to use selenium as a prophylactic treatment in monosodium glutamate exposed individuals.

\section{REFERENCES}

Abd-Ella, E.M.M. and Mohammed, A.M.A. (2016): Attenuation of Monosodium Glutamate-Induced Hepatic and Testicular Toxicity in Albino Rats by Annona Muricata Linn. (Annonaceae) Leaf Extract. Journal of Pharmacy and Biological Sciences, 11(6): 61-69.

Alalwani, D.A. (2013): Mono sodium glutamate induced testicular lesions in rats (histological study). J. Middle East Fertil. Soc., 1: 10171025.

Anane, R. and Creppy, E.E. (2001): Lipid peroxidation as pathway of aluminium cytotoxicity in human skin fibroblast cultures. Hum. Exp. Toxicol., 20(9):477-481.

Assayed, M.; Salem, H. and Khalaf, A. (2008): Protective effects of garlic extract and vitamin $\mathrm{C}$ against 
cypermethrin reproductive toxicity in male rats. J. Vet. Sci., 1(1): 1-15.

Berner, Y.N. and Stern, F. (2004): Energy restriction controls aging through neuroendocrine signal transduction. Aging. Res. Rev., 3: 189-198.

Boodnard, I.P.; Gooz, H.; Okamura, B.E.; et al. (2001): Effect of neonatal treatment with monosodium glutamate on dopaminergic neurons of hypothalamus and on prolactin secretion of rats. Brain Res. Bull., 55:767-774.

Chen, J.G.; Ahn, K.C.; Gee, N.A.; Hammocck, B.D. and Lasley, B.L. (2007): Anti androgenic properties of parabens and other phenolic containing small molecules in personal care products. Toxicol. Appl. Pharmacol., 221: 278-284.

Contini, M. D. C.; Millen, N.; Riera, L. and Mahieu, S. (2012): Kidney and liver functions and stress oxidative markers of monosodium glutamate-induced hepatotoxicity in obese rats. Am. J. Clin. Nutr., 2(5): 168-177.

Das, R. S. and Ghosh, S. K. (2010): Long-term effects of monosodium glutamate on spermatogenesis in albino mice (histological study). Nepal Med. Coll. J., 12: 149-153.

Diab, A. A. and Hamza, R. Z. (2016): Monosodium glutamate induced hepatotoxicity and the possible mitigating effect of vitamin $\mathrm{C}$, selenium and propolis, J. Med. Physiol. Sci., 7(4): 1-10.

Diniz, Y.S.; Faine, L.A; and Galhardi, C.M. (2005): Monosodium glutamate in standard and high-fiber diets: metabolic syndrome and oxidative stress in rats. J. Nutr., 21(6): 749-755.

Egbuonu, A.C.C.; Obidoa, O.; Ezeokonkwo, C.A.; Ezeanyika, L. U. S. and Ejikeme, P.M. (2009): Hepatotoxic effects of low dose oral administration of monosodium glutamate in male albino rats, African J. Biotech., 13(8): 30313035.

Ekaluo, U.B.; Ikpeme, Y.B.; Ibiang, E.V. and Amaechina, O. S. (2013): Attenuating role of vitamin c on sperm toxicity induced by monosodium glutamate in albino rats. Pakistan J. Boil. Sci., 10: 2339.

Erb, J. (2006): The Slow poisoning of mankind. A Report on the toxic effects of the food additive monosodium glutamate. WHO Exp. Comm. Food Add., 5(3): 1-24.

Eweka, A.O. and Om Iniabohs, F.A.E. (2010): Histological studies of the effects of Monosodium glutamate $o$ the fallopian of tubes of adult female Wister rats. Am. J. Med. Sci., 2 (3): 146- 149.

Eweka, A.O.; Igbigbi, P.S. and Uchey, R.E. (2011): Histochemical studies of the effects of monosodium glutamate on the liver of adult Wistar rats. Ann. Med. Health Sci. Res., 1: 21-29.

Farombi, E.O. and Onyema, O.O. (2006): Mono sodium glutamateinduced oxidative damage and genotoxicity in the rat: modulatory role of vitamin $\mathrm{C}$, vitamin $\mathrm{E}$ and quercetin. Hum. Exp. Toxicol., 125: 251-259.

Foyer, C.H.; Pellny, T.K; Locato, V. and De Gara, L. (2008): Analysis of redox relationships in the plant cell cycle: Determinations of 
ascorbate, glutathione in plant cell cultures. Mol. Biol., 476: 199- 215.

Franca, L.R.; Suescun, J.R.; Miranda, A. and Calandra, R. (2006): Testis structure and function in a non-genetic hyperadipose rat model at prepubertal and adult ages. Endocr., 147:1556-1563.

Gheller, A.C.G.V.; Kerkhoff, J.; Júnior, G.M.V.; Campos, K.E. and Sugui, M.M. (2017): Antimutagenic effect of Hibiscus sabdariffa L. aqueous extract on rats treated with monosodium glutamate. The Scientific World Journal, 2017:1-8.

Green, D.R. (2000): Apoptotic pathways: paper wraps stone blunts scissors. Cell, 102: 1-4.

Gropper, S.S.; Smith, J.L. and Groff, J.L. (2009): Microminerals. In: Advanced nutrition and human metabolism. Am. J. Clin. Nutr., 5(12): 469-536.

Gupta, S.; Gupta, H.K and Soni, J. (2005): Effect of vitamin $E$ and selenium supplementation on concentrations of plasma cortisol and erythrocyte lipid peroxides and the incidence of retinal fetal membranes in crossbred dairy cattle, Theriogenol., 64: 12731286.

Hamdy, G. M.; Saleh, E.M. and Seoudi, D.M. (2018): Does Monosodium Glutamate Induce Genotoxic Stress Through Altering Gadd45b Gene Expression? Research Journal of Pharmaceutical, Biological and Chemical Sciences, 9(3): 10581070.

Hamza, R.Z. and AL-Harbi, M.S. (2014): Monosodium glutamate induced testicular toxicity and the possible ameliorative role of vitamin $E$ or selenium in male rats. Reprod. Toxicol., 1: 1037-1045.

Horobin, R. W. and Bancroft, J. D. (1998): Hematoxylin and Eosin as an oversight stain In: Trouble Shooting Histology Stains. $1^{\text {st }}$ ed., Chapter (22), Churchill living stone, Pearson Professional Limited press, New York, London and Madrid, 88 - 93.

Hu, J.; Zhang, Z.; Shen, W.J. and Azhar, S. (2010): Cellular cholesterol delivery, intracellular processing and utilization for biosynthesis of steroid hormones. Nutr. Metab., 7:47-72.

Husarova, V, and Ostatnikova, D. (2013): Monosodium Glutamate Toxic Effects and Their Implications for Human Intake: A Review 2013; 1-12.

Igwebuike, U.M.; Ochiogu, I.S.; hedinihu, B. C.; Ikokide, J. E. and Idika, I. K. (2011): The effects of oral administration of monosodium glutamate on the testicular morphology and epididymal sperm reserves of young and adult male rats. Vet. Archiv., 81: 525-534.

Izuchukwu, S.; David, O.; Chukwuka, N. and Mbegbu, E. C. (2015): Effects of monosodium glutamate administration on serum levels of reproductive hormones, epididymal sperm reserves and testicular histomorphology of male albino rats. Reproduc. Toxicol., 63 (1): 125-139.

John, S.A. (2006): A report on the toxic effects of the food additive, monosodium glutamate. WHO Exp. Comm., 2:124-130. 
Jones, D.P. and Sies, H. (2015): The redox code. Antitoxic. Redox Signal, 23:734-746.

Joslin, J. (2009): Blood collection: Techniques in exotic small mammals. J. Exotic. Pet. Med., 18(2): 117-139.

Kunkel, E.M. and Barbara, H.D. (2004): Food additives and preservatives. The Gale Group Inc., Macmillan Ref. USA, New York, 53(6):383-384.

Kuriyama, K.; Yokoi, R.; Kobayashi, K.; Suda, S.; Hayashi, M.; Ozawa, S.; Kuroda, J. and Tsujii, H. (2005): A timecourse characterization of male reproductive toxicity in rats treated with methyl methane-sulphonate. J. Toxicol. Sci., 30: 91-102.

Marin-Guzman, J.; Mahan, D.C. and Whitmoyer, R. (2000): Effect of dietary selenium and vitamin $\mathrm{E}$ on the ultra structure and ATP concentration of boar spermatozoa, and the efficacy of added sodium selenite on sperm motility. J. Anim. Sci., 78:15441550.

Marwa, A. and Manal, R. (2011): Evaluation of monosodium glutamate induced neurotoxicity and nephrotoxicity in adult male albino rats. J. Am. Sci., 7 (8): 264276.

McIlwain, D.R.; Berger, T. and Mak, T.W. (2013): Caspase Functions in Cell Death and Disease. Cold Spring Harb. Perspect. Biol., 5:a008656.

Messaoudi, I.; Banni, M.; Said, L.; Saïd, K. and Kerkeni, A. (2010): Involvement of selenoprotein $\mathrm{P}$ and GPx gene expression in cadmiuminduced testicular pathophysiology in rats, Chem. Biol. Interact., 188: 94-101.

Nayanatara, A.; Vinodini, N.; Damadar, G.; Ahemed, B.; Ramaswamy, C.; Shabarinath, M. and Bhat, M. (2008): Role of ascorbic acid in mono sodium glutamate mediated effect on testicular weight sperm morphology and sperm count in rat testis, J. Chin. Clin. Med., 3: 1-5.

Ni, H.; Lu, L.; Deng, J.; Fan, W.; Li, T. and Yao, J. (2016): Effects of Glutamate and Aspartate on Serum Antioxidative Enzyme, Sex Hormones, and Genital Inflammation in Boars Challenged with Hydrogen Peroxide. Mediators of Inflamm., (2016): 110.

Noeman, S.A.; Haamode, H.E. and Baalash, A.A. (2011): Biochemical study of oxidant stress markers in the liver, kidney and heart of high fat diet induced obesity in rats. Diabetol. Metab. Syndr., 3:17-25.

Ohkawa, H; Ohishi, N. and Yagi, K. (1979): Assay for lipid peroxides in animal tissues by thiobarbituric acid reaction. Anal. Biochem., 95 (2): 351- 358.

Onyema, O.O.; Farombi, E.O.; Emerole, G.O.; Ukoha, A. I. and Onyeze, G.O. (2006): Effect of vitamin $\mathrm{E}$ on mono sodium glutamate induced hepatotoxicity and oxidative stress in rats. Indian. J. Biochem. Biophys., 43(1): 20-24. Özyurt, H.; Sögüt, S.; Yıldırım, Z.; Kart, L.; Iraz, M.; Armutçu, F.; Temel, I.; Ozen, S.; Uzun, A. and Akyol, O. (2004): Inhibitory effect of caffeic acid phenethyl ester on bleomycine-induced lung fibrosis in rats. Clin. Chem. Acta., 339:65-75. 
Paglia, D. and Valentine, W. (1967): Studies on the quantitative and qualitative characterization of erythrocyte glutathione peroxidase. J. Clin. Med., 70(1): 158-170.

Pisoschi, A.M. and Pop, A. (2015):The role of antioxidants in the chemistry of oxidative stress: A review., 97:55-74.

Raben, A.; Agerholm-Larsen, L.; Flint, A.; Holst, J.J. and Astrup, A. (2003): Meals with similar energy densities have different effects on energy expenditure and substrate metabolism. J. Clin. Nutr., 77:91-100.

Raiten, D.J.; Talbot, J.M. and Fisher, K.D. (1995): Executive summary from the report: Analysis of adverse reactions to monosodium glutamate (MSG). J. Nutr., 125: 2892- 2906.

Rana, H.A.; Nabil, M.T; Abd Elwahab, A.; Mohammed, A. L. and El Morshedy, A. (2016): Effect of monosodium glutamate and sodium nitrite on some biochemical parameters, Am .J. Vet. Sci., 48(1): 107-114.

Reitman, S. and Frankel, S. (1957): A colometric method for the determination of serum glutamic oxalacetic and glutamic pyruvic transaminases. Am. J. Clin. Pathol., 28(1): 56-63.

Richard, J. and Lewis, S. (1990): Monosodium glutamate as a food additive. Food Add. Handbook. Kluwer Acad. Publish., 2: 310-318.

Saied, N.M. and Hamza, A.A. (2014): Selenium ameliorates isotretinoininduced liver injury and dyslipidemia via antioxidant effect in rats. Toxicol., Mech., Methods, 24(6):433-437.
Saito, Y.; Yoshida, Y.; Akazawa, T.; Takahashi, K.; Takahashi, K. and Niki, E. (2003): Cell death caused by selenium deficiency and protective effect of antioxidants. J. Biol. Chem., 278: 3942-3943.

Salem, E.A.; Maarouf, A.M.; Serefoglu, E.C. et al. (2012): Selenium and lycopene attenuate cisplatin-induced testicular toxicity associated with oxidative stress in Wistar rats. J. Urol. Sci., 5:79-84.

Schwartz, J.R. (2004): The monosodium glutamate syndrome. Food Chem. Toxicol., 2:145-150.

Seiva, F. R.F. ; Chuffa, L. G. A.; Braga, C. P. ; Amorim, J. P. A. and Fernandes, A. A. H. (2012): Quercetin ameliorates glucose and lipid metabolism and improves antioxidant status in postnatally mono sodium glutamate-induced metabolic. Food Chem. Toxicol., 50: 3556-3561.

Sener, G.; Sehirli, A.O. and Ayanoglu-Dulger, G. (2003): Melatonin protects against mercury-induced oxidative tissue damage. Pharmacol. Toxicol., 93:290-296.

Shredah, M.T. (2017): Molecular study to the effect of monosodium glutamate on rat gingiva. Tanta Dental Journal, 14: 155-163.

Soliman, A.M. (2011): Extract of coelatura aegyptiaca ameliorates hepatic oxidative stress induced by monosodium glutamate in rats. Indian J. Exp. Biol. , 5(3): 398-408.

Soudani, N.; Ben Amara, I.; Sefi, M.; Serefoglu, E.C. and Hellstrom, W.J. (2010): Effects of selenium on chromium induced hepatotoxicity in adult rats. Exp. Toxicol. Pathol., 63(6):541-8. 
Su, L.; Wabg, M.; Yin, S.T.; Wang, H.L.; Chen, L.; Sun, L.G. and Ruan, D.Y. (2008): The interaction of selenium and mercury in the accumulations and oxidative stress of rat tissues. Ecotoxicol. Environ. Saf., 70(3): 483-489.

Swelim, H.H. (2004): Monosodium glutamate induced retinopathy in adult and neonate mice. Egypt. J .Med. Lab. Sci., 13:45-71.

Szewczuk, A.; Kuropatwa, M. and Lang, D. (1988): Colorimetric method for assay of serum gammaglutamyl transferase activity with some L-gamma-glutamylcarboxyanilides. Clin. Chim. Acta., 178(1):35-40.

Tawfik, M.S. and Al -Badr, N. (2012): Adverse effects of monosodium glutamate on liver and kidney functions in adult rats and potential protective effect of vitamins $C$ and $E$. Food and Nutr. Sci., 3: 651-659.

Tezcan, E.; Atmaca, M.; Kuloglu, M. and Ustundag, B. (2003): Free radicals in patients with posttraumatic stress disorders, Eur. J. Psychiat. Neurosci., 253: 86-91.

Thapaliya, S.; Wree, A.; Povero, D.; Inzaugarat, M.E.; Berk, M.; Dixon, L.; Papouchado, B.G. and Feldstein, A. E.(2014):
Caspase 3 inactivation protects against hepatic cell death and ameliorates fibrogenesis in a diet induced NASH model. Dig. Dis. Sci., 59(6): 1197-1206.

Thomas, M.; Sujatha, K.S. and George, S. (2009): Protective effect of Piper longum Linn. on monosodium glutamate induced oxidative stress in rats, Indian $\mathrm{J}$. Exp. Biol., 47(3):186-92.

Tremellen, K. (2008): Oxidative stress and male infertility a clinical perspective. Hum. Reprod. Update, 14: 243- 58.

Walke, R. and Lupien, J.R. (2000): The safety evaluation of monosodium glutamate. In: International symposium on glutamate. Nutr., 130: 1049 - 1052.

Yan, Y.C.; Sun, Y.P.; Zhang, M.L. and Koide, S.S. (1998): Testis epidermal growth factor and spermatogenesis. Arc. Androl., 40: 133-146.

Zirkin, B. and Chen, H. (2000): Regulation of leydig cell steroidogenic function during aging. Biol. Reproduc., 63: 977981. 
تقييم دور السيلينيوم فى التسمم الكبدي والخصي المحدث بالجلوتامات أحادية الصوديوم في الجرذان البيضاء

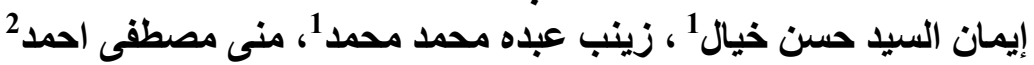

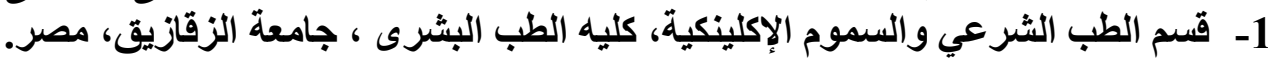

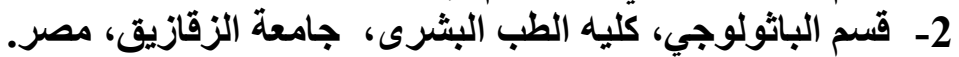

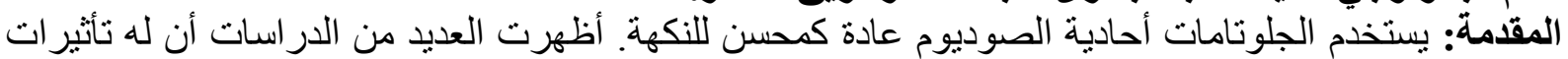
سامة على مختلف الأعضاء. يمتلك السيلينيوم خاصية قوية مضادة الكادة للألكسدة.

الهدف: تقييم دور السيلينيوم في التسمم الكبدي وتسمم الخصية الناجمين عن تناول جلوتامات أحادية الصوديوم في ذكور الجرذان البيضاء.

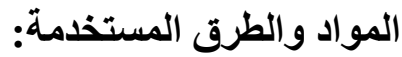

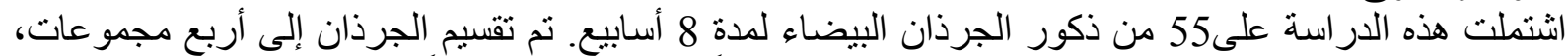

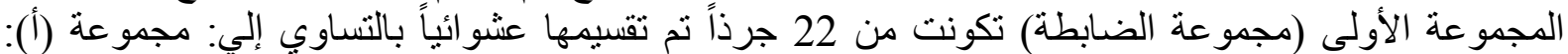

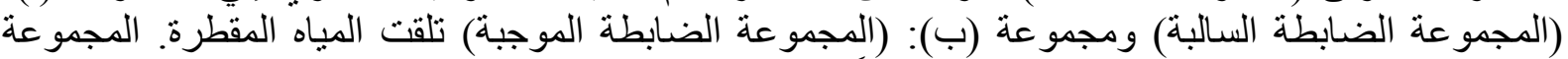

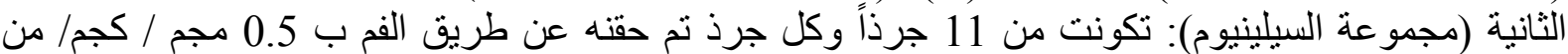

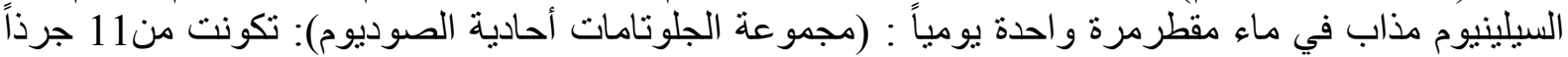

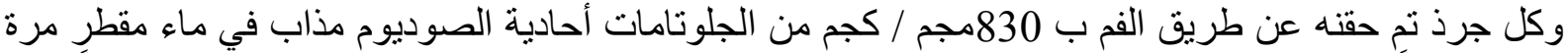

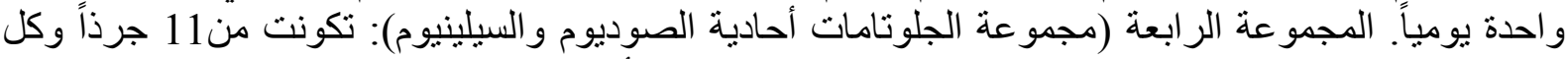

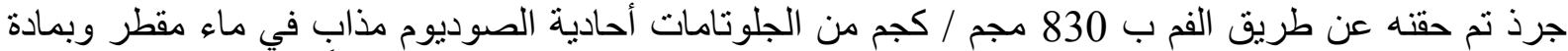

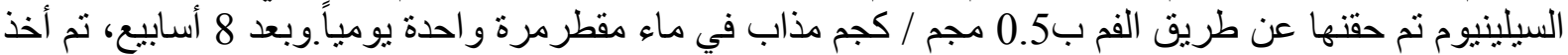

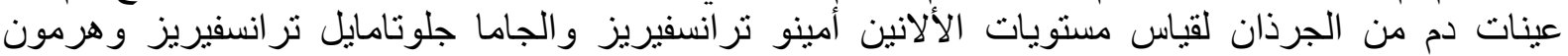

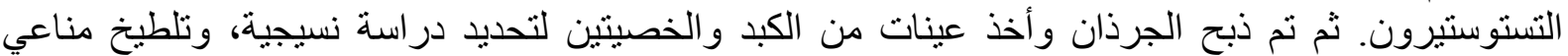
للكاسباس الثلاثي ،قياس دلانلات الإجهاد التأكسدي في أنسجة الكبد والخصية عن طريق قياس نسبة

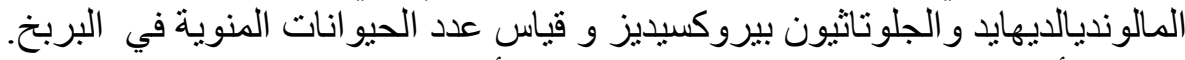

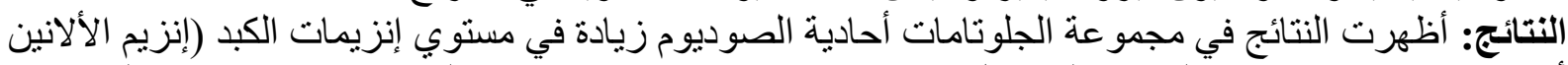

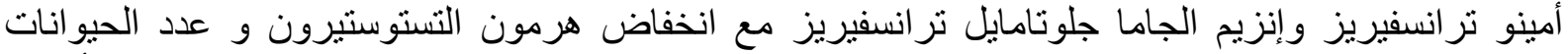

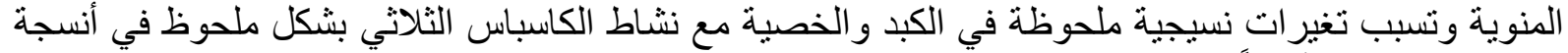

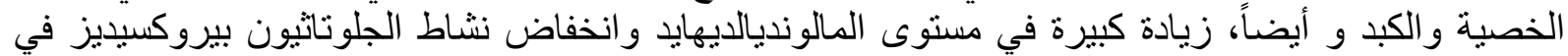

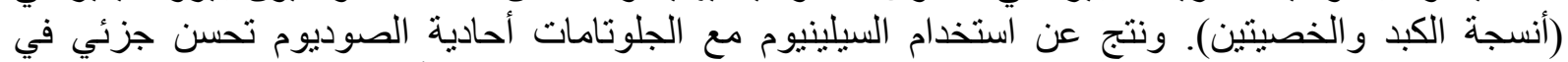
التغيرات النسيجية للخصية والكبد، وانخفاض في التعبير الكاسباس الثنلاتي مع تأثير مفيد على إنزيمات التيات الكبد

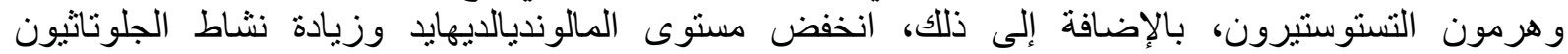

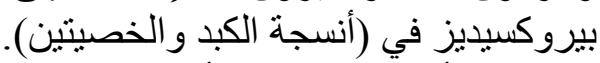

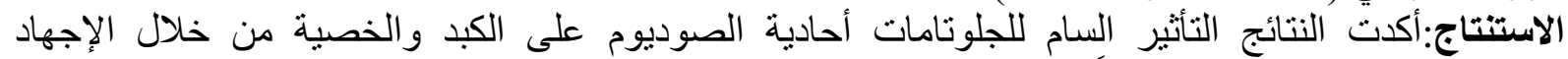

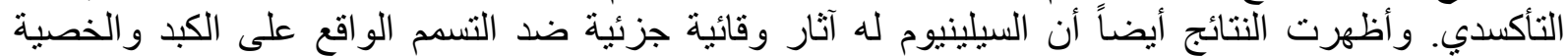

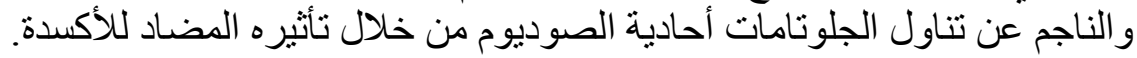

